\title{
Tinea Imbricata
}

\section{Bajpai $\mathbf{M}^{1 *}$, Pardhe $\mathbf{N}^{1}$ and Vijay $\mathbf{P}^{2}$}

${ }^{1}$ Department of Oral and Maxillofacial Pathology, NIMS Dental College, India

${ }^{2}$ Department of Oral Pathology and Microbiology, King George's Medical University, India

*Corresponding author: Bajpai M, Department of Oral and Maxillofacial Pathology, NIMS Dental College, Jaipur, India

Received: December 04, 2017; Accepted: December 12, 2017; Published: December 19, 2017

\section{Clinical Image}

An 8 year old presented with the chief complaint of several itchy hypo pigmented scars on her left side of face since 2 months, but other parts of her body were normal. Skin scrapings were microscopically examined in $\mathrm{KOH} 10 \%$ and numerous irregular, branch and septate hyaline hyphae were observed. The patient was successfully treated with oral terbinafine $250 \mathrm{mg}$ /day, topical clotrimazole ( $1 \%$ ointment), topical miconazole $(2 \%$ cream) two times daily and potassium permanganate for daily washing for four weeks. After 1 year of follow up no complaint, reported about the relapse of infection (Figure 1).

Tinea imbricata is an unusual form of tinea corporis caused by the strictly anthropophilic dermatophyte T. concentricum.

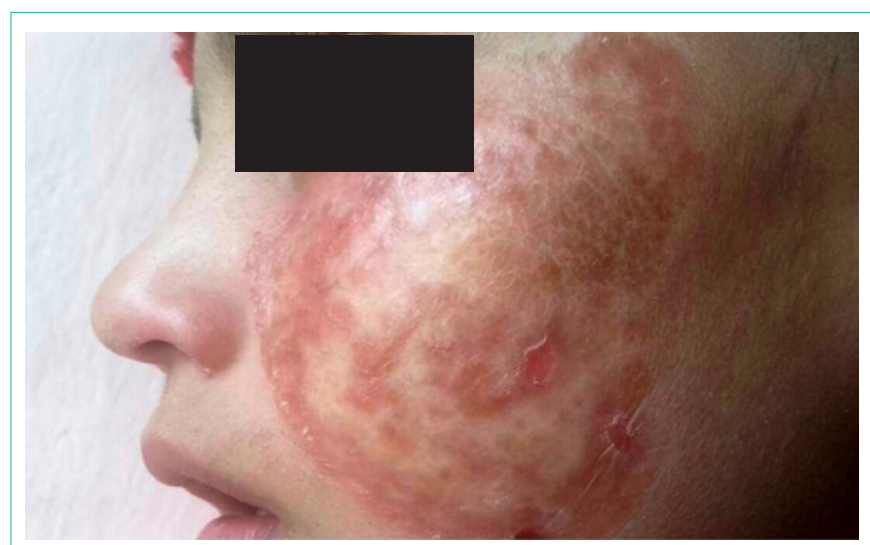

Figure 1: Erythematous itchy lesion of face. 